santhenum-Blüthe, wechselt die Farbe. Jetzt erscheint das reich betakelte Thier im lebendigsten Röthlichblau, wie spanischer Hollunder; kurz darauf geht die ganze Gestalt, mit Ausnahme der Spitzen, in das heiterste Grün des Frühlings über, um darin die Hollunderblüthen wandernd spielen zu lassen und eine perlige Blume zu spielen. Dann ist es wieder ganz Hollunderblüthe, die Farbe verduftet und grint wieder in eine Farbe über, wie man sie nicht schöner durch ein von der Sonne beschienenes Blatt des Lenzes sehen kann. In der Provence macht man aus dieser Species ein Lieblingsgericht, genannt "Rastegna“. Ueberhaupt giebt es unter diesen zahlreichen Völkern der Tiefe wohl noch ganz andere Delicatessen, als Krebssuppe, Hummersalat, die englischen Shrimps und die kosmopolitischen Austern. Holen sich doch die Plebejer Londons täglich ganze Fuder Schnecken mit Stecknideln aus deren schwarzen Gehäusen!

Jetzt, nachdem die Völker rer Oceane und unterseeischen Höhlen, Berge und Thäler zum Theil Lieblinge der feinsten Gesellschaften in englischen drawing-rooms (Staatszimmern) geworden sind, wird man viclleicht einige vor Liebe aufessen lernen. Als Putzzimmer-Decorationen gelten die Marine-Aquarien mit den lebendigen Wundern der Meerestiefe zwischen den krystallenen $W$ änden, klar und durchsichtig auf dem Tische, als eine der schönsten, originellsten und malerischesten Ausschmückungen englischer Häuslichkeit. In Deutschlind scheut man noch deren Kostspieligkeit.

\title{
Aus dem botanischen Garten zu Breslau.
}

\section{I.}

Unter dieser Aufschrift beabsichtige ich von Zeit zu Zeit über wissenschaftliche und allgemein interessante Verhältnisse, Gewächse etc. des botanischen Gartens zu Lurichten, zunächst über ein auserordentlich rasches 
Wachsthum, wie es bis jetzt wenigstens noch bei keiner andern Pflanze beobachtet worden ist. Vor $12 \mathrm{Jah}$ ren erhielt ich aus Holland zwei Exemplare des danals noch sehr seltenen Pandanus furcatus Roxb. von der Grösse gewöhnlicher Ananaspflanzen, die seit der Zeit zn Stämmen von $18-22$ Fuss Höhe mit zahlreichen Blättern von 15 Fuss Länge herangewachsen sind und Hauptzierden unseres Palmenhauses ausmachen. Bei einer Demonstration der grössern dieser interessanten Pfanze am 2. Mai war von einer Blïthenentwickelung nichts zu sehen, den 4 ten Abends zeigten sich an der Spitze einige weisse, mit ihren Spitzen geschlossene Blätter und an andern Morgen war aus ihnen eine traubige, fast 1 Zoll dicke und bereits 3 Fuss lange Blüthentraube hervorgetreten mit 10-14 Zoll langen, 2-3 Zoll breiten Bläittern, in deren Winkeln eben so viele, unsern Teichkolben (Typha) ähnliche, 6-8 Zoll lange, $11 / 2$ Zoll dicke Aehren sich befanden, welche Millionen gelblich weisse, nur aus Staubgefïssen bestehende Blïthen enthielten. Dis Verlängerungr erfolgte nun langsamer, die Blïthenrispe senkte sich, hatte aber dennoch in der kurzen Zeit von 36 Stunden die enorme Lïnge von 5 fuss erreicht. Ebenso schnell begann das zweite Exemplar am 13. Mai Abends in Blüthe zu treten, und obschon kaum zu erwartende Umstände auch hier eine exacte Beobachtungr in kurzen $Z$ wischenriumen verhinderten, ergab sich doch, dass die grösste Längenentwickelung von $3 \frac{1}{1} 2$ Fuss in dem Verlauf von 4-5 Stunden statt gefunden hatte. Die Länge des Stiels betrug hier 31/4 Fuss, die der Bliithentraube $2^{1 / 2}$ Fuss, also das Ganze fast 6 Fuss. Man hätte hier in der That das Wachsthum sichtbar verfolgen können, wie dies Miquel gelungen ist, der innerhalb 3 Stunden den Kolben um 3 Fuss sich verlïngern sah*). Viel-

*) Der Blütheustengel von Ayave americana wïchst durchschnittlich nur 2 Fuss in jeder Woche, der von Dasijlirion etwas rascher, $10-12$ Zoll täglich. 
leicht glückt es uns das nächste Mal, diese wunderbare Erscheinung, bei welcher ich auch noch die Entwickelung hoher Temperaturgrade bemerkte, in ihrem ganzen Verlaufe zu beobachten. Der Blïthenkolben selbst wird neben der Mutterpflanze bei einem aus Java stammenden Fruchtkolben derselben Art im Palmenhause aufgestellt. Verwandtes physiologisches Interesse bietet ein in der Nähe des Wassergrabens an der kleinen Weinlaube angestelltes, Jedem zugängliches Experiment. Eine auf einer Weinrebe durch Kautschuk befestigte Glasröhre zeigte das schnelle Steigen des Saftes, welches von Beginn der Vegetation bis zum Ausschlagen der Blätter dauert, und bis zur Höhe von 36 Fuss erfolgt, wie ich vor einigen Jahren beobachtete. Hales sah das in eine Röhre gegossene Quecksilber 38 Zoll sich erheben, was einer Wassersäule von 43 Fuss $33 / 4$ Zoll Höhe gleichkommt, worauf also die das Wasser in die Höhe treibende Kraft den Druck von 21/2 Atmosphïren auszuhalten vermöchte und fünfmal stärker wäre als die Kraft, welche das Blut in die Schenkel der Schlagadern eines Pferdes treibt. Es liegt auf der Hand, dass diese Erscheinung nicht durch rein physikalische Momente, wie etwa durch Haarröhrchen-Anziehung, wie Einige meinen, sondern nur durch die organische Thätigkeit der Zellen erklärt werden kann. An einem Orte des Gartens, der auch physiologische Zwecke zu verfolgen sich vorzugsweise zur Aufgabe stellt, sieht man als Product des Bildungssaftes in einer Weide, die auf Stanniolblättchen abgelagerten Jahreslagen derselben u. dergl. Die zahlreichen bei uns eingeführten Arten der Pomaceen, Amygdaleen, welche fast durchweg der gemässigten Zone der nördlichen Halbkugel angehören, stehen nun in Blüthe, unter ihnen auch die japanischen, welche sich durch Schönheit der Farben und Blüthenreichthum, nicht aber durch Trefflichkeit der Früchte auszeichnen, wie die Obstcultur mit der der Blumen tuberhaupt dort nicht gleichen Schritt zu halten scheint. Die in der That sehr reich blühende Malus Toringa und flo- 
vibunda sind von Pyrus baccata nicht verschieden. $\mathrm{Zu}$ Zierden der in der Nähe befindlichen japanischen Parthie gehören vor allen jetzt die Magnolien, die Formen der Mognolir Yulan, Sonlangenna, aus China, Lenneana, wie auch die nordamerikanische $M$. curiculata, acuminuta. Die Flora des hohen Nordens und der Alpen beginnt sich immer mchr zu entfalten. Ich komme später darauf zuriick, erwähne hier nur, bereits die fiir die Bewohner des hohen Nordens durch seine wohlschmeckenden Früchte besonders wichtigen Rubus arcticus, Cornus suecica, die Zierde der Haine Skandinaviens, und Cypripedium macranthum, der sibirische Frauenschuh, überaus grossbliithige Erdorchideen, Pupaver nulicaule nach Franklin, die härteste Pfanze der arktischen Regionen etc. Fin Rhododemanon manoliaefolizm vom Himalaja, mit wohlriechenden liliengrossen Blüthen auf der neu eingerichteten Eriken. partie, links von der Kastanienallée, lässt auf die grossartigen Verhältnisse der alpinen Flora jenes interessantesten Gebirges der alten Welt schliessen. Dic Aufstellungen gehen ihrer Beendigung entgegen, unter ihnen diesmal auch der im vorigen Iorbst und Winter grezonene Pilz des in so vieler Berichung so überaus interessanten Mutterkornes (Claviceps purpureu).

Breslau, den 16. Mai 1865. H. R. Göppert.

\section{Pharmakologische Notizen; von \\ Dr. X. Landerer.}

In einer französischen Zeitschrift wurde mitgetheilt, dass durch Einathmen des Leuchtgases der Paroxismus des Keuchhustens bedeutend gemildert werde und die damit behatteten Kinder in kurzer Zeit davon geheilt wïrden. Da nun auch in Athen eine Leuchtgas-Anstalt existirt, so theilte die Direction diese Mittheilung durch die Zeitungen mit und erbot sich, denjenigen, die dasselbe einzuathmen gesonnen seien, dasselbe gratis zu ge- 